\title{
Incorporating sustainability as a primary design fundamental in residential architecture: a case study analysis of a single-family residence
}

\author{
R. J. Michal \& N. V. Chalfoun \\ University of Arizona College of Architecture and Landscape \\ Architecture, USA
}

\begin{abstract}
As recorded in the earliest existing written work of architecture, The Ten Books on Architecture written by Vitruvius in $27 \mathrm{BC}$, one of the primary goals of architecture has been to strike the balance between "Firmness, Commodity and Delight" or structural integrity, functional efficiency, and aesthetic beauty. While the terms "sustainability" and "sustainable architecture" were not coined until the late twentieth century, Vitruvius' treatise did incorporate the underlying concepts of sustainability: resource efficiency, human thermal comfort and recognition of regional environmental factors, under the category of commodity.
\end{abstract}

Beginning in the late nineteenth century however, with technological advances in materials and the introduction of modern mechanical systems, these underlying sustainable concepts appeared to have been forgotten and commodity was reduced to a focus primarily on spatial relationships. These changes in design values have come at a cost. This is evidenced first by the ever-increasing dependency of modern forms on fossil fuel driven mechanical systems to create and maintain optimal human thermal comfort. This is also evidenced by the decreasing presence of uniquely regional architectural forms. The ubiquitous use of homogenous universal or "placeless" architectural forms such as interchangeable residential housing tracts and retail strip malls represent the pursuit of brand recognition and economies of scale offered by universal standardization at the expense of regional and climatically appropriate architectural design.

The purpose of this paper is to critically review and analyze the impacts on architectural form, function and appearance of a case study residence located in the extreme arid climate of the Sonoran desert in the Southwest United States, in which the concept of sustainability was incorporated as one of the primary design fundamentals. The case study residence is an approximately 2,000 square foot home built for a family of five with four bedrooms and two bathrooms and a separate attached guest bedroom and bath. This paper will provide an overview and analysis of the case study residence in terms of: 1) the original project values and goals as represented by the design and computer energy modeling process and 2) the project results as captured by the qualities (structural and aesthetic) of the final constructed physical form and its post-occupancy performance (functional, spatial and resource conservation).

Keywords: sustainability, thermal comfort, thermal mass, regional, energy efficient, passive solar. 


\section{Introduction}

\subsection{The University of Arizona Graduate School of Architecture}

The Graduate School of Architecture at the University Arizona is comprised of three focus areas: "Design and Energy Conservation," "Urban Design," "Preservation Studies," and "Emerging Materials." As part of the graduate design and energy conservation program students enroll in courses including solar utilization, energy efficiency in high-rise structures, alternative building material design-build studio, as well as two computer energy analysis classes. Computer energy analysis and advanced computer energy analysis are part of the School of Architecture's "House Energy Doctor" (HED) program.

\subsection{The House Energy Doctor}

HED is a program that provides education and research experiences for students as well as no cost energy consultation and design prescription services for homeowners [1]. The advanced methods taught to students provide them with the necessary skills to conduct computer energy analysis and performance predictions utilizing CalPas 3 computer energy simulation software. The House Energy Doctor residential analysis is performed through a ten-step procedure starting from the site survey and ending with conclusions and recommendations for improving energy consumption of buildings.

\subsection{The community of Civano}

During the spring semester of 2002, students and faculty in the HED program selected the community of Civano as the site for investigation of the thermal performance of alternative building envelope systems. Civano is a mixed-use development located in Tucson, Arizona intended in part to showcase passive solar and energy conservation designs in residential housing. While Civano was originally envisioned to be the "Solar Village," the project was subsequently modified to incorporate "Neo-Traditional" or "New Urbanism" design characteristics. While these added design criteria provided benefits for the community as a whole, they also may have resulted in significant compromises in the thermal performance of some of the homes within the community.

The five residences selected for the study each utilized a unique alternative building material envelope system. These systems included adobe, Integra block, strawbale, metal stud framing with rigid insulation (Heydon system) and structurally insulated panels (SIPs).

As a result of this study the authors concluded that generally there are two distinct approaches to energy efficient design. The first approach can be best described as the "super insulated box." This approach involves the use of highefficiency heating and cooling equipment and minimizing heat gain or loss through the building envelope. This is typically accomplished by using a high $\mathrm{R}$-value envelope and minimizing exterior wall and roof surface area as well as 
window and door penetrations. This approach does not rely on solar orientation. The second approach can be best described as the "thermal mass" home. Unlike the super insulated box, this approach relies on a high volume of thermal mass walls with good passive solar orientation. This approach also relies on fenestration for solar gain and natural ventilation. This approach is less dependent on the use of high-efficiency equipment and high R-value envelope systems.

\section{Purpose: a passive solar case study residence}

In May of 2002, one of the authors, a graduate student in the energy program in the School of Architecture, purchased a lot within the Community of Civano with the intention of designing and building an energy efficient thermal mass passive solar showcase home as part of his Master's Thesis.

The intent of the project was not only to apply the findings from the previous research, but also to re-introduce sustainability and the use of traditional regional materials as primary guiding design principles. By equally balancing these two principles along with functional efficiency, structural integrity and aesthetics it was posited that not only could superior thermal performance be achieved, but that the resulting built form would be one that was unique, innovative and lasting.

In this paper the authors intend to document how the integration of sustainable systems and concepts as well as traditional regional materials impacted the homes design and its resulting thermal performance, spatial quality and aesthetic character.

For the purpose of this paper the design process will be broken down into eight primary focus areas of consideration. These eight areas represent some of the focus areas developed by Dr. Chalfoun and used in the HED curriculum. They include: orientation, fenestration, shading, shape, size, material selection, ventilation, and mechanical systems.

\subsection{Orientation, fenestration, and shading}

Tucson is located in the Sonoran Desert within the arid southwest of the United States. Tucson experiences an average of 360 days of sunshine each year. The summer cooling season can span for up to seven months from April through October. July is the warmest month with an average high temperature of $98.5 \mathrm{~F}$ and an average low of 73.8F. Radiant heat from direct solar gain is one of the greatest obstacles to overcome in designing for optimal thermal performance. Orientation, fenestration (size, type and location), and shading are the three most important focus areas or strategies for controlling solar gain.

Even though the 6,213-square-foot, rectangular-shaped building lot purchased for the project was oriented 27.5 degrees off of north south, it was determined that the front elevation should be rotated off of the property line to face due south. This orientation (combined with the placement of windows and shading overhangs) was selected to shade out the high summer sun along the south 
façade during the summer while still allowing the lower winter sun to passively heat the home and charge the thermal mass during the winter. Since the south façade is the only elevation that allows the seasonal optimization of solar gain, $45 \%$ of the home's windows were located within this façade. Unwanted solar gain was minimized by reducing the glazing along the east and west facades. In addition to shading the west façade against the harsh late afternoon summer sun, the detached garage and a series of rainwater harvesting aquaducts were located on the west side of the home. Unwanted solar gain was also minimized through the use of low-e glass in all windows.

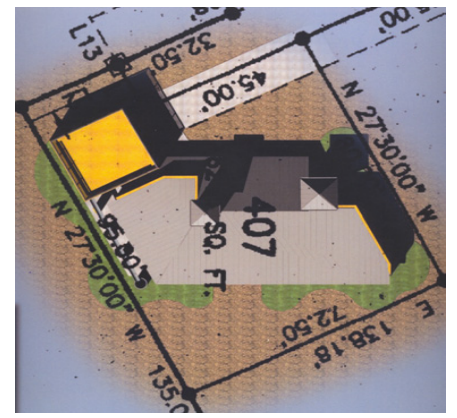

Figure 1: $\quad$ Site plan with passive solar oriented building footprint.

Most residential dwellings on this size lot and almost all of the homes within Civano tend to follow the property line. By changing the orientation of the south elevation or front façade and not following property line, fundamentally altered both the homes passive solar and thermal performance but also its architectural character.

\subsection{Size and shape}

One of the advantages of the desert climate is that its moderate winter temperatures allow year-round outdoor living. For this reason outside living space was optimized to reduce the amount of required indoor space. As a result, the amount of indoor conditioned space was reduced by approximately 500 square feet or from approximately 2250 square feet to 1750 square feet (The exterior wall mass and cool tower added 250 square feet of unconditioned interior space). The functional spaces moved outdoors include: an outdoor dining room, outdoor sleeping porch, an outdoor or "cowboy" shower, garage rooftop patio and the laundry room (located in the unconditioned detached garage).

This enabled the dwellings design to not only reduce the amount of conditioned space and therefore fossil fuel consumption but also to incorporate an architectural concept of attempting to blur the line between interior and exterior spaces. Unlike traditional homes where there is a clear formal segregation functionally and spatially between the interior and exterior, the use of appropriately placed glazing, screen walls, door openings and roof overhangs 
allowed typically interior located functions to be relocated to exterior spaces such as the outdoor dining and sleeping porch and the outdoor or "cowboy" shower.

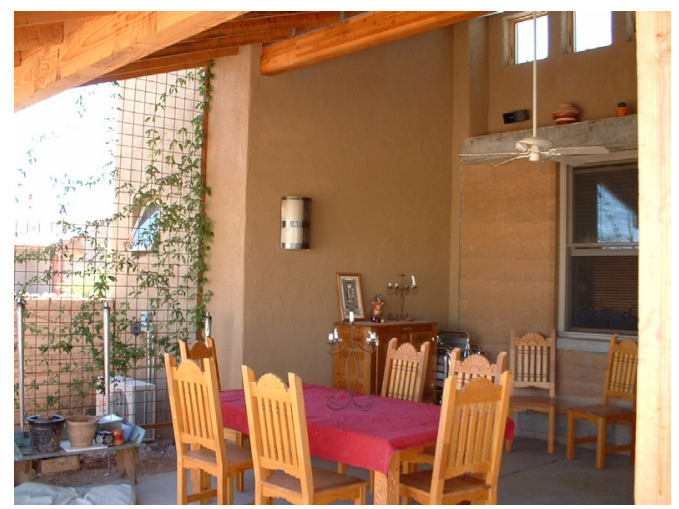

Figure 2: North facing outdoor dining porch (photograph by Wilson Graham).

\subsection{Material selection}

Based upon the design's advantageous solar orientation and the large amount of exterior wall area created by the carving out of the numerous outdoor spaces, it was determined that a thermal mass wall system should be utilized. Thermal mass wall systems are ideal because they allow the home to take advantage of the large daily temperature swings that occur in the Sonoran Desert. In summer exposed interior thermal mass absorbs radiant heat during the day keeping the indoor temperature low. The absorbed heat can then be released from the thermal mass through natural ventilation at night, when the outdoor temperature drops 20 to 30 degrees $\mathrm{F}$.

The palette of local thermal mass wall building materials includes concrete, concrete masonry units, adobe brick, and rammed earth. Of these two thermal mass wall systems were integrated into the design.

The first of the two wall materials selected was rammed earth. Rammed earth was selected for its strength, beauty, thermal mass properties, sustainability, and the relative inexpensiveness of its raw materials. Similar to the concrete flooring, the rammed earth served as its own finished material, requiring no additional façade or cladding. An additional benefit of the rammed earth is that it represents a low-tech building system, enabling the author with the assistance of unskilled volunteer labour to undertake the construction of this system himself.

The other wall system selected was 8 " x 8" x 16 " standard concrete masonry units. Masonry was selected for its thermal mass, the relative availability and inexpensiveness of the material and the labour to construct it. Masonry represents the most common building material used in local residential 
construction during most of the $20^{\text {th }}$ century. Adobe brick was considered as well based on its thermal mass and aesthetic qualities and its pre- $20^{\text {th }}$ century history as the predominant building material. Adobe brick was not selected, however, because of its additional expense.

While both of these wall systems proved more costly in terms of time and material and labour costs in comparison to typical wood framed residential construction, they fundamentally altered and enhanced the homes thermal performance, aesthetic character, structural integrity and the dwellings literal and figurative longevity or sense of lasting. Also the use of these materials allowed for the expression of these materials themselves as interior finishes, which reduced and in some cases eliminated the need for the application of additional interior facia or finishes which enhances the sustainability of the structure, reduces the cost and adds to the quality and character of the spatial experience.

\subsection{Insulation}

The majority of heat loss and gain that occurs in a residence is through the ceiling/roof system. For this reason, above ceiling insulation is critical. Two ceiling insulation systems were selected.

The first ceiling insulation system, selected for the east and west more private bedroom wings of the residence, was a five-component built-up system. This system from top down was comprised of the roofing material, a layer of $1 / 2$ " exterior sheathing, steel trusses, R38 blown-in cellulose insulation, R6.5 thermal break attached to the underside of the steel trusses and finally a layer of $1 / 2$ " drywall to serve as the ceiling 9' above the finish floor. In addition in the bathrooms and corridors another $1 / 2$ " drywall ceiling was added below this ceiling at $8^{\prime}$ above finish floor to serve as a plenum for mechanical ductwork and to minimize any duct losses to unconditioned space.

The second ceiling insulation system was selected for the central section of the home to allow the incorporation of large vaulted ceilings and south-facing clerestory windows in the more public and open family room and kitchen spaces. This second system was a structurally insulated panel system (SIPs). This single panel made up of $91 / 2$ " of polystyrene adhered between two sheets of $1 / 2$ " oriented strand board (OSB), represents an all-in-one system that provides sheathing underneath the roofing material, a structural panel that can span 23', an insulation value of R38 and a layer of $1 / 2$ " OSB to serve as a finish ceiling.

The SIPs panels are not only sustainable because of their high $\mathrm{R}$ value, but also because they represent a single building system that serves the purpose of multiple systems: They serve as the underlayment for the standing seam metal roof; eliminate the need for any roof joists; eliminate the need for additional insulation; and by exposing and sealing the OSB on the underside of the panels, they eliminate the need for installing additional ceiling finishes such as wood or drywall.

\subsection{Ventilation}

In order to enhance natural ventilation and to minimize the consumption of energy required to maintain thermal comfort all of the windows specified for 
installation are operable. Operable windows provide thermal gain, day lighting and views, as well as ventilation and passive cooling. As mentioned previously, natural ventilation is also necessary to enhance the performance of the thermal mass systems by allowing them to discharge the stored heat to the cooler night hours.

To further enhance natural ventilation and to allow for micro-climate control of thermal comfort, 12 ceiling fans have been incorporated into all of the indoor living spaces and four of the outdoor living spaces. While ceiling fans require energy to operate they require substantially less energy than typical air conditioning. They also have the advantage that they can more easily be individually isolated for operation in only those areas being occupied at the time.

\subsection{Passive and mechanical systems}

There are three primary mechanical systems: passive cooling, passive heating, and an active or standard heat pump system for backup heating and cooling only when necessary.

The primary passive heating incorporated into the design is the home's passive orientation, window placement and thermal mass. During the winter the solar gain allowed into the residence from the south should heat the thermal mass and interior. To enhance this solar gain, the south-facing sleeping porch has also been designed to operate as a sunspace. This sunspace is designed to have two glass operable overhead doors that will allow the solar gain to be trapped in this space during the winter, similar to a green house, so that warm air can be distributed throughout the rest of the residence. To prevent overheating during the summer, the operable glass overhead doors will be lifted and left in their open position.

The primary cooling is the passive downdraft evaporative cooling system. It is a 30'-tall cool tower. A cool tower is a form of evaporative cooler that works by distributing cool humid air generated from forcing dry air through watersoaked cellulose pads. Unlike most evaporative coolers, however, a cool tower does not rely on a fan to distribute the cool humid air, but instead relies on gravity to generate the necessary airflow. The cool tower designed for the project provides $16^{\prime}$ of elevation from the bottom of the cellulose pads to the top of the discharge below. The 16' drop should provide approximately 4,500 cubic feet per minute of airflow to distribute the cool humid air throughout the residence. The primary disadvantage of cool towers and evaporative coolers is that they are not effective during periods of high humidity (such as the annual monsoon season in late July and August). Mechanical air conditioning systems are required for only back-up use during these hot and humid periods.

The back-up active mechanical heat pump system was designed with the assistance of $\mathrm{Al}$ Nichols, a local professional mechanical engineer and recognized designer of energy efficient mechanical systems. For further efficiency, the residence has been split into two separate systems. The first system is a SEER 12 forced air 3 ton split heat pump system to serve the main living, and bedroom areas. The second system is a 1-ton mini split heat pump to serve the attached guest bedroom and bath. This two-system split design allows 
each system to be more centrally located within the areas served and therefore provides more efficient operation and distribution. It also allows the separate smaller area to be more easily isolated and operated only during periods when the space is occupied.

The incorporation of the passive evaporative cooling system not only significantly impacts the dwelling's thermal performance but it also serves architecturally as a visual and structural anchor to the design. The southwest and northeast corners of the masonry tower are 16"x16" steel reinforced masonry columns that provide structural support for two of the roof's primary structural members as well as the south facing clerestory. The $5^{\prime}$ by $5^{\prime}$ by $30^{\prime}$ tall tower projects out of the center of the home making it one of the most dominant architectural features of the home.

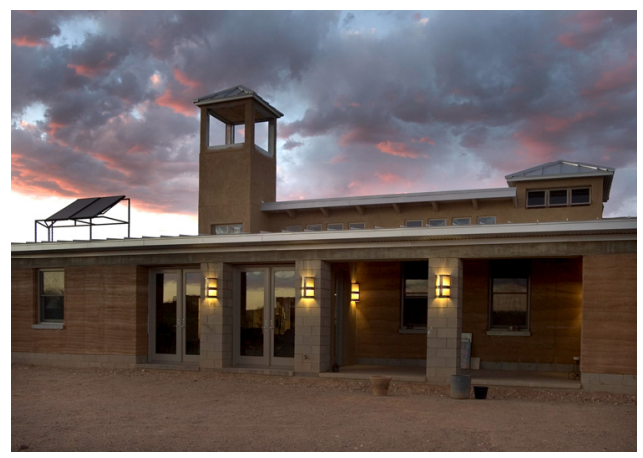

Figure 3: $\quad$ South facade of residence (photograph by Wilson Graham).

A second smaller tower was also incorporated into the home's design. This shorter stockier approximately $20^{\prime}$ tall tower, serves several functions. First functionally its footprint houses the master bathroom. Second, it enhances the thermal performance of the dwelling by housing the highest windows in the home. These windows are necessary in order to allow hot air to escape and therefore to draw the evaporative cooled air east through the family room and into the master bedroom. Structurally, like the cool tower to the west, it serves as a structural support for the east end of the clerestory windows and roof. Finally, architecturally it serves as a second vertical mass to balance and moderate the vertical mass of the cool tower.

\section{Conclusion}

For the twelve-month operating period from February 2005 through January 2006 , for a family of five, the home's total annual heating and cooling cost was only $\$ 185.55$ or $\$ 15.46$ per month. The home performed at a level of $\$ 0.09$ per square foot per year compared to the average Tucson home, which has been found to perform at a level of $\$ 0.75$ per square foot per year. 
Structurally, compared to wood framing the homes 24" deep continuous reinforced concrete footings, 24" wide rammed earth walls, steel reinforced 8" masonry walls and continuous reinforced concrete bond beams the home is better designed to withstand wind and seismic loads and the test of time, long outlasting conventional construction.

Aesthetically, the home through the expression of its exposed rammed earth walls, two massive towers, atypical shape and orientation, outdoor living areas, clerestory windows, and the integration of its other sustainable systems and regional materials, is truly unique and innovative.

\section{References}

[1] Chalfoun, N.V. (1991). The "House Energy Doctor@"; An Educational, Research and Community Service Program at the College of Architecture, The University of Arizona. 1991 Design for Desert Living Symposium, Jul. 21-26, Tucson, AZ, U.S.A. 